Cite this: RSC Adv., 2014, 4, 10269

\title{
Fluorescent nitric oxide detection using cobalt substituted myoglobin $\dagger$
}

\author{
Trevor D. Rapson, ${ }^{\star}$ Helen Dacres and Stephen C. Trowell
}

Received 16th December 2013

Accepted 31st January 2014

DOI: $10.1039 / c 3 r a 47658 h$

www.rsc.org/advances

We report two advances in optical biosensing of nitric oxide (NO). Firstly, we developed an improved biomolecular gated system for fluorescent transduction of heme-NO binding. Secondly, through a cobalt substitution, the detection limit for NO was decreased an order of magnitude lower than that of native myoglobin.

Nitric oxide (NO) sensors are useful for a variety of applications ranging from pollution monitoring to clinical diagnostics and biomedical research. ${ }^{1-3}$ Elevated NO levels in breath have been used as a marker for the diagnosis of airway inflammation in asthma and chronic obstructive pulmonary disease, allowing early diagnosis and intervention. ${ }^{4}$ Bioimaging of in situ NO production has allowed the elucidation of its many biological roles. ${ }^{2}$ While there are a number of NO sensors commercially available, ${ }^{5-8}$ there is a need for cheap and compact NO breath sensors to enable early detection of asthma attacks and new methods for detecting NO in vivo. Biosensors could provide a useful option for developing cheaper and more selective NO sensors. ${ }^{6,7}$

Heme proteins are ideal recognition elements for gases such as oxygen and NO. Soluble guanylate cyclase (sGC), a heme protein, can bind nitric oxide in preference over other gases such as oxygen. ${ }^{9}$ While a number of heme proteins have been tested for their suitability as NO optical sensors, they do not have the sensitivity provide by techniques such as chemiluminescence or electrochemistry. Furthermore, immobilisation of heme proteins can adversely affect both their response and reversal times. ${ }^{10-14}$

In order for heme proteins to be effectively used as optical biosensors, their sensitivity needs to be increased and limits of detection (LOD) needs to be reduced. In this study, we sought to improve the sensitivity of heme protein based optical transducers using two approaches. The first involves developing an

CSIRO Ecosystem Sciences and Food Futures Flagship, GPO Box 1700, 2601, ACT, Australia.E-mail: trevor.rapson@csiro.au; Fax: +612 62464000; Tel: +61262464104 $\dagger$ Electronic supplementary information (ESI) available. See DOI: $10.1039 / \mathrm{c} 3 \mathrm{ra} 47658 \mathrm{~h}$ efficient fluorescent method to detect NO binding to heme proteins. The second involves using a metal substituted myoglobin, cobalt myoglobin (CoMb) to decrease the LOD for NO.

We employed a relatively new fluorescent method known as biomolecular gating. ${ }^{15}$ In this approach, the fluorescence intensity of a fluorophore is modulated by the differing amount of light absorbed by a heme protein in the NO-bound or NO-free state. The heme protein effectively acts as a wavelength selective filter, limiting the exciting light reaching the fluorophore (Scheme 1). ${ }^{15}$

In the first reported biomolecular gating system, Strianese et al. ${ }^{15}$ employed two heme proteins; cytochrome c peroxidase and myoglobin to measure NO and $\mathrm{O}_{2}$ binding respectively. Fluorescein immobilised on a nitrocellulose membrane, excited at $450 \mathrm{~nm}$, was used as the fluorophore. Although the authors

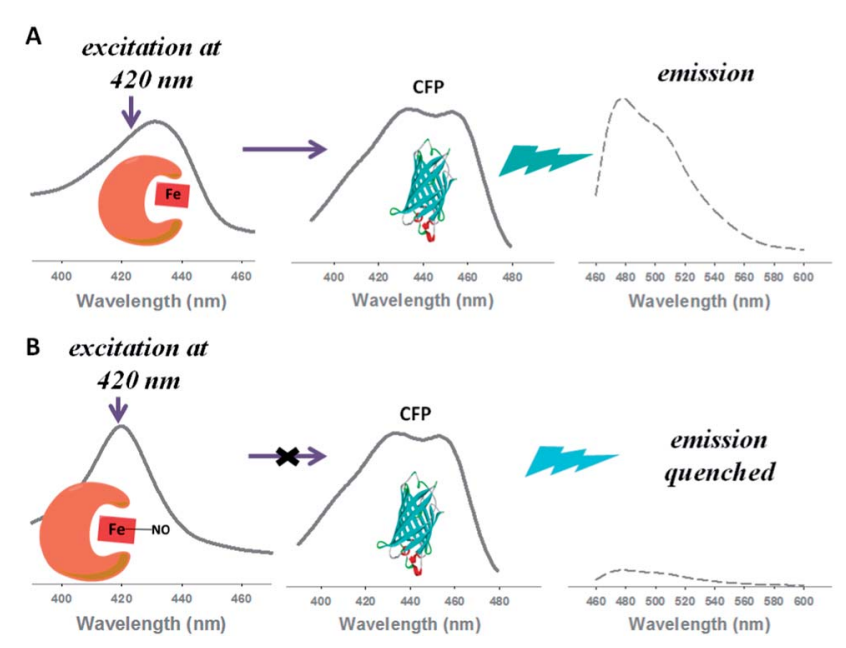

Scheme 1 Cartoon representation of the principle of biomolecular gating. Myoglobin (Mb) acts as a filter modulating the emission of cyan fluorescent protein (CFP). (A) Represents the scenario without nitric oxide present. (B) Represents the scenario with $\mathrm{NO}$ bound to $\mathrm{Mb}$, leading to a shift in the Soret peak from $430 \mathrm{~nm}$ to $420 \mathrm{~nm}$. This spectral shift leads to a quenching of emission from CFP. 


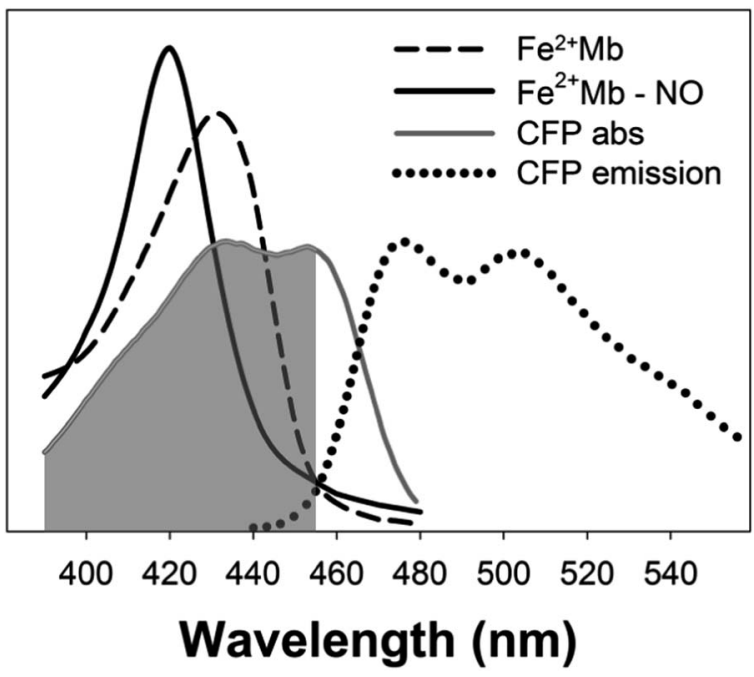

Fig. 1 Absorption spectra of cyan fluorescent protein (CFP abs) with reduced myoglobin $\left(\mathrm{Fe}^{2+} \mathrm{Mb}\right)$ and nitric oxide bound myoglobin $\left(\mathrm{Fe}^{2+} \mathrm{Mb}-\mathrm{NO}\right)$ and the emission spectrum of CFP. The overlapping area of the absorption spectra is highlighted in grey.

were able to convert absorption changes into either an increase or decrease in fluorescence, quantitative analysis of gas binding was not reported.

The key to an efficient molecular gating system is to optimise the overlap between the excitation band of the fluorophore and one or more of the absorption bands of the gas binding protein. ${ }^{15}$ In order to improve the efficiency of biomolecular gating we chose a fluorophore with a large spectral overlap with heme proteins in the $400-430 \mathrm{~nm}$ region. Cyan fluorescent protein (CFP) with absorption maxima at $435 \mathrm{~nm}$ and $455 \mathrm{~nm}$ has large spectral overlap with reduced, oxidised and nitric oxide bound myoglobin (Fig. 1). Fluorescent proteins in biosensors are also advantageous to small molecular dyes such as fluorescein as they have greater photostability. ${ }^{16} \mathrm{~A}$ further modification to the procedure reported by Strianese $e t a l .{ }^{15}$ was to have both the fluorophore and NO binding protein in solution rather than immobilising the fluorophore on a membrane.

With CFP as the fluorophore, we used excitation wavelengths of $400-430 \mathrm{~nm}$. The changes in the position of the Soret peak with increasing dissolved NO concentration (generated by diethylamine NONOate, see ESI $\dagger$ ) were converted into quantitative fluorescence changes (Fig. 2). When exciting at $420 \mathrm{~nm}$, the increase in absorption at $420 \mathrm{~nm}$ of myoglobin with $\mathrm{NO}$ (Fig. 2B) led to a decrease in CFP emission at $480 \mathrm{~nm}$ (Fig. 2C). Conversely, the decrease in myoglobin absorption at $430 \mathrm{~nm}$ (Fig. 2B) led to an increase in CFP fluorescence when exciting at $430 \mathrm{~nm}$ (Fig. 2C). No fluorescence changes were seen with the addition of NO to CFP.

The biomolecular gating system with myoglobin and CFP was optimised for the "gating" effect of myoglobin. Optimal concentrations of $15 \mu \mathrm{M}$ and $0.65 \mu \mathrm{M}$ for myoglobin and CFP respectively were determined. Using the optimised conditions, there was $\sim 85 \%$ decrease in the initial fluorescence signal with excitation at $420 \mathrm{~nm}$, substantially greater than the $20 \%$ decrease previously reported with fluorescein. ${ }^{15}$
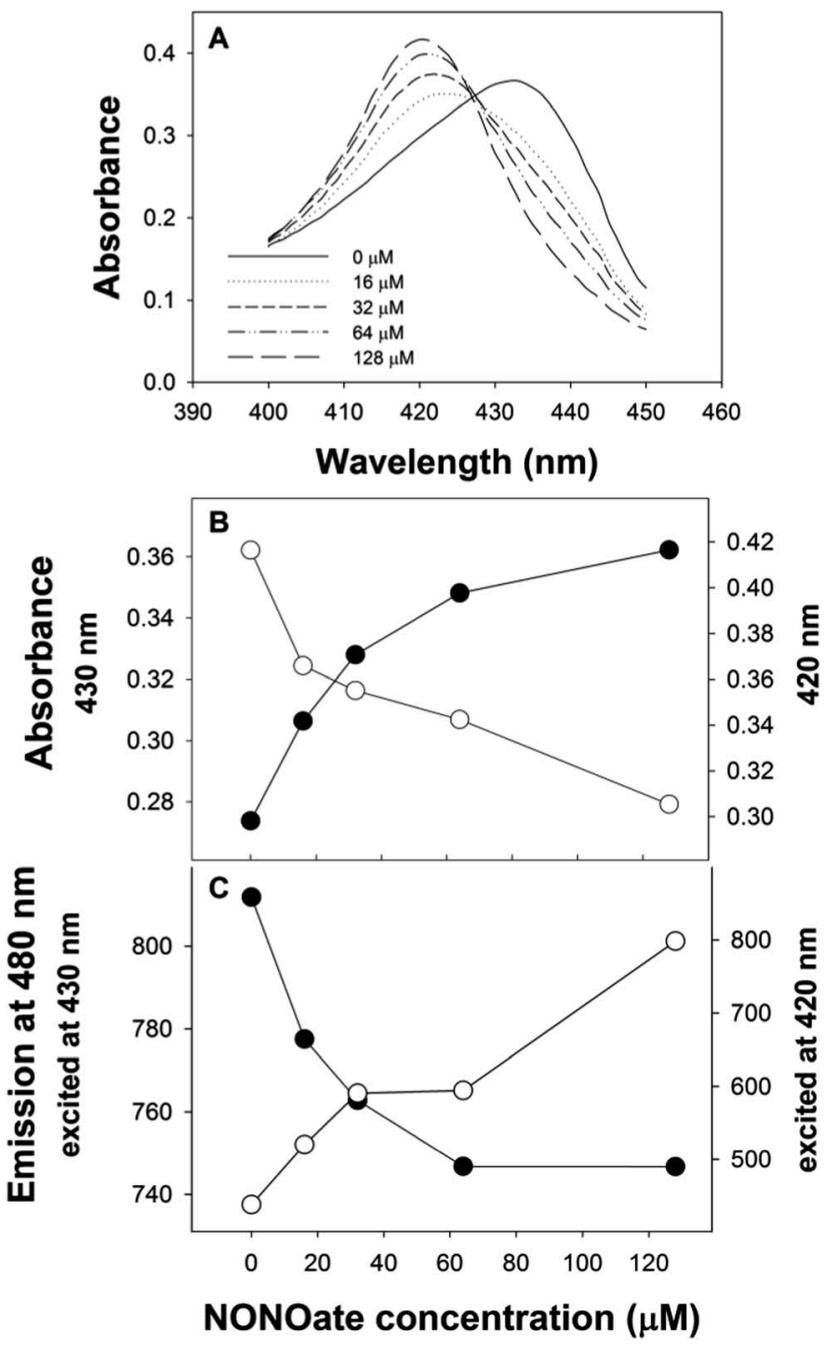

Fig. 2 (A) The effect of increasing dissolved NO concentration, generated by diethylamine NONOate, on the absorption spectra of reduced myoglobin. (B) The changes in absorption of reduced myoglobin at $420 \mathrm{~nm}$ (black circles) and $430 \mathrm{~nm}$ (open circles). (C) The changes in emission of CFP in a biomolecular gated system using cyan fluorescent protein (CFP) to transduce the spectral changes in Mb with $\mathrm{NO}$ binding excited at $430 \mathrm{~nm}$ (left $y$-axis) and $420 \mathrm{~nm}$ (right $y$-axis).

Initially, both 420 and $430 \mathrm{~nm}$ were used as excitation wavelengths. However, excitation at $420 \mathrm{~nm}$ was found to give improved reproducibility and larger changes in emission compared to excitation at $430 \mathrm{~nm}$. Using an excitation wavelength of $420 \mathrm{~nm}$, with myoglobin, a linear region between 0-30 $\mu \mathrm{M}$ NO was obtained and it was possible to determine the dissociation constant $\left(K_{\mathrm{d}}\right)$ of NO binding (Fig. 3).

We hypothesised that an iron to cobalt substitution could improve the limit of detection for NO. CoMb (where iron protoporphyrin IX has been substituted with cobalt protoporphyrin IX) has been used previously to study the function of oxygen binding heme proteins such as hemeoglobin and myoglobin. CoMb has a number of properties which could make it ideal for use as a NO sensor. Firstly, $\mathrm{Co}^{2+} \mathrm{Mb}$ has a lower oxygen affinity (50-100 times larger partial pressure of oxygen, $p_{0.5}$ ) than native myoglobin, ${ }^{17,18}$ while showing an intrinsically 


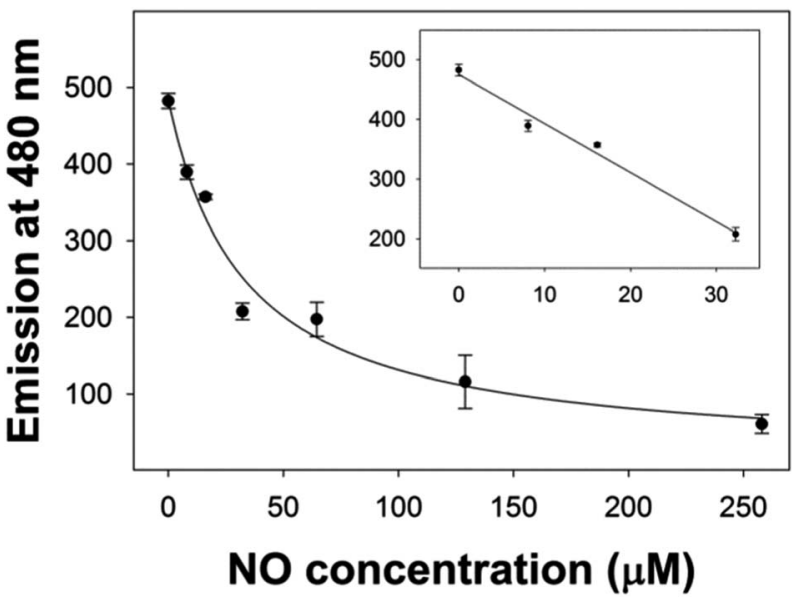

Fig. 3 Quantitative analysis of dissolved NO binding (generated from diethylamine NONOate) to myoglobin monitored using the emission of cyan fluorescent protein (CFP) at $480 \mathrm{~nm}$, excited at $420 \mathrm{~nm}$. The insert shows the linear region from $0-30 \mu \mathrm{M}$ nitric oxide.
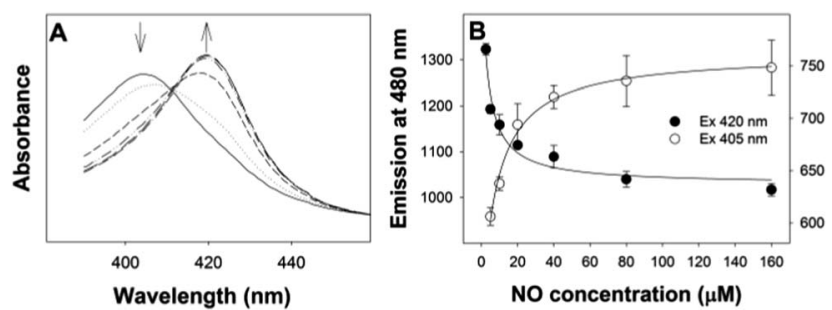

Fig. 4 (A) Shift in the Soret peak from $405 \mathrm{~nm}$ to $420 \mathrm{~nm}$ of CoMb with increasing dissolved $\mathrm{NO}$ concentrations, generated by diethylamine NONOate (arrows indicate the direction of changes with increasing NO). (B) Quantitative analysis of NO binding monitoring the emission of cyan fluorescent protein at $480 \mathrm{~nm}$. Excitation wavelengths of both $405 \mathrm{~nm}$ (right $y$-axis) and $420 \mathrm{~nm}$ (left $y$-axis) were used.

greater reactivity toward NO. ${ }^{19}$ Furthermore, CoMb does not bind carbon monoxide ${ }^{18}$ and has decreased affinity for nitrates and nitrites. ${ }^{20}$

Laverman and Ford carried out mechanistic studies of NO reactions with iron and cobalt porphyrin complexes. They reported a larger formation constant for $\mathrm{Co}^{2+}$ porphyrins $\left(1.3 \times 10^{13}\right.$ $\left.\mathrm{M}^{-1}\right)$ compared to $\mathrm{Fe}^{2+}$ porphyrins $\left(2.4 \times 10^{12} \mathrm{M}^{-1}\right){ }^{21}$ No one, however, has investigated the suitability of $\mathrm{CoMb}$ for use as an optical NO biosensor. We, therefore used our biomolecular gating system, to compare NO binding properties of FeMb and CoMb.

The Soret peak of $\mathrm{Co}^{2+} \mathrm{Mb}$ shifts from $405 \mathrm{~nm}$ to $420 \mathrm{~nm}$ on NO binding (Fig. 4A). Using CoMb, quantitative analysis of NO binding was carried out at both $405 \mathrm{~nm}$ and $420 \mathrm{~nm}$. We observed that $\mathrm{Co}^{2+} \mathrm{Mb}$ was less readily oxidised than $\mathrm{Fe}^{2+} \mathrm{Mb}$ giving data with lower variance and improved reproducibility for $\mathrm{Co}^{2+} \mathrm{Mb}$ when tested under both aerobic and strict anaerobic conditions. Again, $420 \mathrm{~nm}$ is the preferred excitation wavelength as we observed less scatter compared to excitation at 405 nm (Fig. 3B).

In order to quantitatively compare the suitability of $\mathrm{FeMb}$ and CoMb for use in NO sensing, we determined their $K_{\mathrm{d}}$ and
Table 1 Comparison of the limits of detection reported for NO heme protein based optical sensors

\begin{tabular}{|c|c|c|c|}
\hline Heme receptor & $\begin{array}{l}\text { Transduction } \\
\text { method }\end{array}$ & $\begin{array}{l}\text { Limit of } \\
\text { detection }\end{array}$ & Reference \\
\hline Cytochrome c & Absorbance & $1 \mathrm{ppm}$ & 24 \\
\hline Cytochrome $\mathrm{c}^{\prime}$ & Absorbance & $10 \mu \mathrm{M}$ & 12 \\
\hline Myoglobin & Absorbance & n.d. & 25 \\
\hline$T t \mathrm{H}-\mathrm{NOX}^{a}$ & Absorbance & $0.3 \mu \mathrm{M}$ & 14 \\
\hline Cytochrome $\mathrm{c}^{\prime}$ & FRET $^{b}$ & $8 \mu \mathrm{M}$ & 11 \\
\hline $\begin{array}{l}\text { Soluble } \\
\text { guanylate } \\
\text { cyclase }\end{array}$ & FRET $^{b}$ & $1 \mu \mathrm{M}$ & 10 \\
\hline $\begin{array}{l}\text { Cytochrome } \\
\text { c peroxidase }\end{array}$ & $\mathrm{FRET}^{b}$ & n.d. $\left(K_{\mathrm{d}}=10 \mu \mathrm{M}\right)$ & 13 \\
\hline $\begin{array}{l}\text { Cytochrome } \\
\text { c peroxidase }\end{array}$ & Biomolecular gating & n.d. & 15 \\
\hline Myoglobin & Biomolecular gating & $1 \mu \mathrm{M}(30 \mathrm{ppb})$ & This work \\
\hline
\end{tabular}

LOD when excited at $420 \mathrm{~nm}$. The same NONOate solutions were used to allow direct comparison. FeMb had a $K_{\mathrm{d}}$ of $32 \pm$ $10 \mu \mathrm{M}$ while the $K_{\mathrm{d}}$ of CoMb was three times lower at $10 \pm 2 \mu \mathrm{M}$. There was a significant reduction in the LOD of dissolved NO from $10 \mu \mathrm{M}$ for FeMb to $1 \mu \mathrm{M}$ for CoMb.

This ten-fold decrease in the limit of detection for dissolved NO obtained using CoMb demonstrates that Co substitution could improve the sensitivity of heme protein-based NO sensors. The use of metal substitution has been reported for other heme proteins. Recently, Marletta and co-workers developed an innovative system where metal substitution is carried out during protein expression rather than traditionally used denaturing conditions. ${ }^{22}$ Therefore, the use of metal substituted heme proteins in biosensors is becoming more convenient and reliable. ${ }^{23}$

In addition to the decrease in the limit of detection, a cobalt substitution introduces a number of other useful properties. The lower affinity of $\mathrm{CoMb}$ for carbon monoxide and nitrates, ${ }^{18,20}$ is potentially an advantage if the sensor were to be used for environmental testing.

The limit of detection obtained with the CoMb/CFP molecular gated system is comparable to the best heme fluorescent system reported to date of $1 \mu \mathrm{M}$ for soluble guanylate cyclase (sGC) (Table 1), ${ }^{10}$ albeit the FRET sGC system was immobilised. A limit of detection of $1 \mu \mathrm{M}$ NO in solution is equivalent to a concentration of $30 \mathrm{ppb}$, this is within the useful range for measurement of NO in breath. In this study we have been measuring dissolved NO generated by diethylamine NONOate to compare FeMb and $\mathrm{CoMb}$, future work will involve measuring NO from gas mixes and ultimately breath samples in order to develop a NO biosensor for the early detection of asthma attacks.

It may be possible to extend the use of biomolecular gated detection to in vivo tissue imaging. Fluorescent proteins have been widely used for biological imaging, ${ }^{16}$ therefore using a biomolecular gating system with heme and fluorescent proteins, we will determine if it is possible to detect NO production in vivo. 
We used cobalt substituted myoglobin for this study as cobalt substitutions in the protein have been well characterised. There are a number candidate heme proteins which could be used in a NO sensor, such as $T t$ H-NOX (Table 1). ${ }^{\mathbf{9 1 4 , 2 3}}$ The findings presented here suggest that it could be worthwhile investigating cobalt substitutions in a range of heme proteins to determine if lower detection limits can be obtained.

\section{Conclusions}

Using CFP and myoglobin we have developed an improved molecular gating system which allowed quantitative analysis of NO binding. The LOD of a myoglobin nitric NO detection system was improved from $10 \mu \mathrm{M}$ to $1 \mu \mathrm{M}$ through an iron to cobalt substitution. These are promising advances in the development of optical biosensors for nitric oxide.

\section{Notes and references}

1 S. M. Cristescu, D. Marchenko, J. Mandon, K. Hebelstrup, G. W. Griffith, L. A. J. Mur and F. J. M. Harren, Appl. Phys. B, 2012, 110, 203.

2 T. Nagano and T. Yoshimura, Chem. Rev., 2002, 102, 1235.

3 N. Kumar, V. Bhalla and M. Kumar, Coord. Chem. Rev., 2013, 257, 2335.

4 A. F. Gelb, P. J. Barnes, S. C. George, F. L. M. Ricciardolo, G. DiMaria and N. Zamel, J. Breath Res., 2012, 6, 047101.

5 R. Dweik, P. Boggs, S. Erzurum and C. Irvin, Am. J. Respir. Crit. Care Med., 2011, 184, 602.

6 C. I. L. Justino, T. A. Rocha-Santos, A. C. Duarte and T. A. Rocha-Santos, Trends Anal. Chem., 2010, 29, 1172.

7 S. Griveau and F. Bedioui, Anal. Bioanal. Chem., 2013, 405, 3475.

8 S. Jiang, R. Cheng, X. Wang, T. Xue, Y. Liu, A. Nel, Y. Huang and X. Duan, Nat. Commun., 2013, 4, 1.
9 E. R. Derbyshire and M. A. Marletta, Annu. Rev. Biochem., 2012, 81, 533.

10 S. L. Barker, Y. Zhao, M. A. Marletta and R. Kopelman, Anal. Chem., 1999, 71, 2071.

11 S. L. Barker, R. Kopelman, T. E. Meyer and M. A. Cusanovich, Anal. Chem., 1998, 70, 971.

12 D. J. Blyth, J. W. Aylott, J. W. Moir, D. J. Richardson and D. A. Russell, Analyst, 1999, 124, 129.

13 M. Strianese, F. De Martino, V. Pavone, A. Lombardi, G. W. Canters and C. Pellecchia, J. Inorg. Biochem., 2010, 104, 619.

14 E. M. Boon and M. A. Marletta, J. Am. Chem. Soc., 2006, 128, 10022.

15 M. Strianese, A. Varriale, M. Staiano, C. Pellecchia and S. D'Auria, Nanoscale, 2011, 3, 298.

16 N. C. Shaner, P. A. Steinbach and R. Y. Tsien, Nat. Methods, 2005, 2, 905.

17 T. Yonetani, H. Yamamoto and G. Woodrow, J. Biol. Chem., 1974, 682.

18 B. M. Hoffman, Proc. Natl. Acad. Sci. U. S. A., 1970, 67, 637.

19 Y. Kholodenko, E. A. Gooding, Y. Dou, M. Ikeda-Saito and R. M. Hochstrasser, Biochemistry, 1999, 38, 5918.

20 J. L. Heinecke, J. Yi, J. C. M. Pereira, G. B. Richter-Addo and P. C. Ford, J. Inorg. Biochem., 2012, 107, 47.

21 L. E. Laverman and P. C. Ford, J. Am. Chem. Soc., 2001, 123, 11614.

22 J. J. Woodward, N. I. Martin and M. A. Marletta, Nat. Methods, 2007, 4, 43.

23 M. B. Winter, E. J. McLaurin, S. Y. Reece, C. Olea, D. G. Nocera and M. A. Marletta, J. Am. Chem. Soc., 2010, 132, 5582.

24 J. W. Aylott, D. J. Richardson and D. A. Russell, Chem. Mater., 1997, 9, 2261.

25 D. J. Blyth, J. W. Aylott, D. J. Richardsonb and D. A. Russella, Analyst, 1995, 120, 2725. 